\title{
Synthesis and charaterization of gold nanoparticles synthesized from a biomaterial
}

\author{
Sana Ansari*, Harsha Devnani* and Soami P. Satsangee \\ University Science Instrumentation Centre, Dayalbagh Educational Institute, Dayalbagh, Agra- \\ 282005(India) \\ *Email: ansarisana969@ymail.com; harsha.devnani@gmail.com
}

In the field of nanotechnology, biosynthesis of nanoparticles has received a considerable attention due to the growing need of developing clean, renewable and environmentally benign solvents $[1,2]$. In the present work, we report a green and inexpensive route for the synthesis of gold nanoparticles (Au-nps) by a simple procedure using vetiver root extract as the reducing agent, without the intervention of any man-made chemicals.

Addition of vetiver root extract to $\mathrm{Au}$ salt solution resulted in change of colour from yellow to violet-red indicating the formation of Au-nps. This was confirmed using UV-VIS spectrophotometry technique. The absorbance peak was centered near $545 \mathrm{~nm}$ as shown in Figure 1. The surface characterization of the synthesized gold nanoparticles was done with scanning electron microscopy (SEM) as shown in Figure 2.

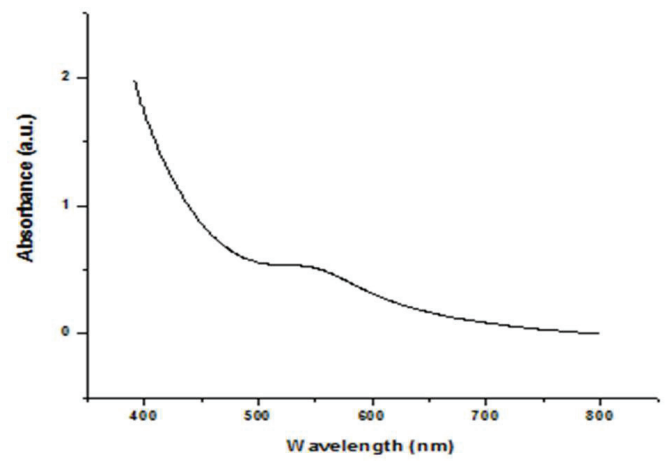

Figure 1: UV-Vis spectrum of Au-nps synthesized from vetiver root extract

$\mathrm{X}$-ray diffraction (XRD) analysis was done in order to study the nature of synthesized Au-nps. From the XRD data, it was confirmed that the Au-nps synthesized by the present green method were crystalline in nature. The average particle size was calculated using DebyeScherrer equation and was found to be in the range 38 to $45 \mathrm{~nm}$. Figure 3 shows the XRD pattern of Au-nps.

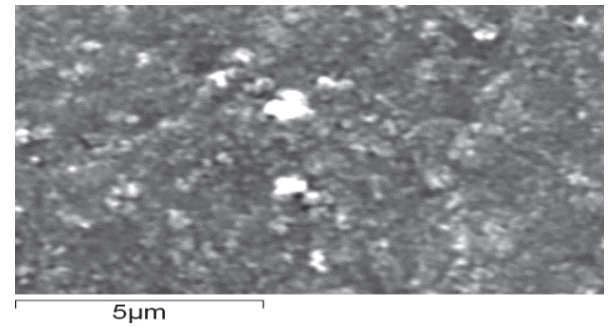

Figure 2: SEM image of synthesized (Au-nps) from vetiver root extract

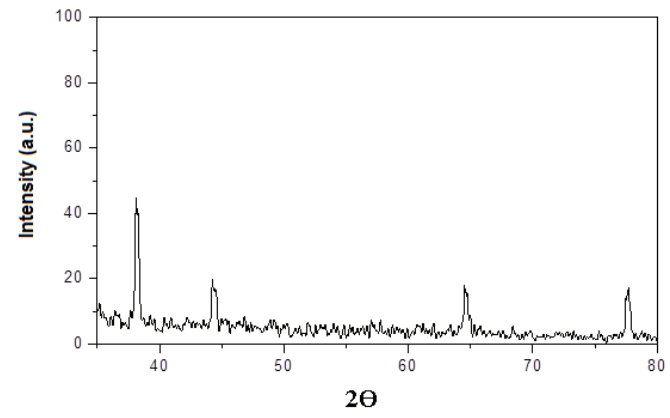

Figure 3: XRD pattern of Au-nps synthesized from vetiver root extract

The proposed method follows $100 \%$ green approach and gold nanoparticles synthesized by this route were found to be stable. The phytochemicals present in the plant extract act as reducing agent for synthesis of the gold nanoparticles, which hold great potential for a variety of applications in various fields.

\section{References}

1. M. Gericke, A. Pinches, Hydrometallurgy, vol. 83, pp. 132-140, 2006.

2. A.T.Harris, R. J. Bali, Nanopart. Res., vol. 10, pp. 691-695, 2008. 